\title{
A new species of Psephenothrips (Thysanoptera: Phlaeothripidae) from China
}

\author{
XIAOLI TONG ${ }^{*}$, CLIVE SIU-KI LAU ${ }^{2} \&$ CHAO ZHAO ${ }^{3}$ \\ ${ }^{1}$ Department of Entomology, College of Plant Protection, South China Agricultural University, Guangzhou 510642, Guangdong, China. \\ (1) https://orcid.org/0000-0003-1731-229X \\ ${ }^{2}$ The Agriculture, Fisheries and Conservation Department, Hong Kong Special Administrative Region, China. \\ (1) https://orcid.org/0000-0001-7629-3696 \\ ${ }^{3}$ College of Food Science and Engineering, Henan University of Technology, Zhengzhou 450001, China. \\ (1) https://orcid.org/0000-0002-5350-9586 \\ *Corresponding author: "xtong@scau.edu.cn
}

\begin{abstract}
A new species of Phlaeothripinae, Psephenothrips aporosae sp. n., is described based on specimens collected in leaf galls on Aporosa octandra [Phyllanthaceae] in China. The new species is characterized by the head being much shorter than wide, the tube slightly longer than the head, and the metanotum with close longitudinal reticulation.
\end{abstract}

Key words: Gall-inducing thrips, Phlaeothripinae, Liothrips lineage, new species

\section{Introduction}

The genus Psephenothrips was erected originally for a single species from Philippines (Reyes 1994), but subsequently seven further species have been added (Reyes 1994; Okajima 2006; Tiyagi \& Kumar 2012; Wang \& Lin 2020; Dang et al. 2021). Okajima (2006) reviewed this genus and considered it as one of the members of the leaffeeding Liothrips-lineage suggested by Mound and Marullo (1996). However, Psephenothrips is not distinguished satisfactorily from the worldwide genus Liothrips Uzel that comprises almost 280 species (Mound 2020) and is particularly species-rich in tropical and subtropical Asian countries. Species in both genera have a single sense cone on antennal segment III, and three sense cones on segment IV; maxillary bridge usually absent; pronotum with 5 pairs of major setae; prosternum lacking basantra; fore wings parallel-sided, usually with duplicated cilia; abdominal tergites II-VII each with two pairs of sigmoid setae; tube usually shorter than head. The main differences are that Psephenothrips species tend to have elongate maxillary stylets that reach into the eyes and are close together in the middle of head capsule, and the five pairs of pronotal major setae are less stout and with knobbed apices. Furthermore, the males lack a pore plate on sternite VIII (Reyes 1994; Okajima 2006; Dang et al. 2014). Whereas in Liothrips species, the length of maxillary stylets is variable, at most extending to the posterior margin of eye; the pronotal major setae usually well developed and elongate; sternite VIII of male usually with a pore plate. Currently, eight species of the genus are known from the world, all recorded only from Asia (ThripsWiki 2021), and all considered to be leaf-feeding species. However, a new Psephenothrips species described below is found from leaf galls (Figs 2-4) on Aporosa octandra [Phyllanthaceae] (Fig. 1) in Hong Kong and Hainan, China. The genus Aporosa was classified under the family Euphorbiaceae for a long time, but is now transferred to family Phyllanthaceae, one of the five segregates of Euphorbiaceae recognized by the Angiosperm Phylogeny Group (Hoffmann et al. 2006). A. octandra is widely distributed throughout South and Southeast Asia up to southern China, and is a pioneer species capable of growing into a $9 \mathrm{~m}$ tall tree in open ground with plenty of sunlight. In shady secondary forest, the plant grows as a shrub up to a height of about $2 \mathrm{~m}$. The aim here is to describe this new gall-inducing thrips in order to facilitate reports on its biology and control in a follow-up study. 


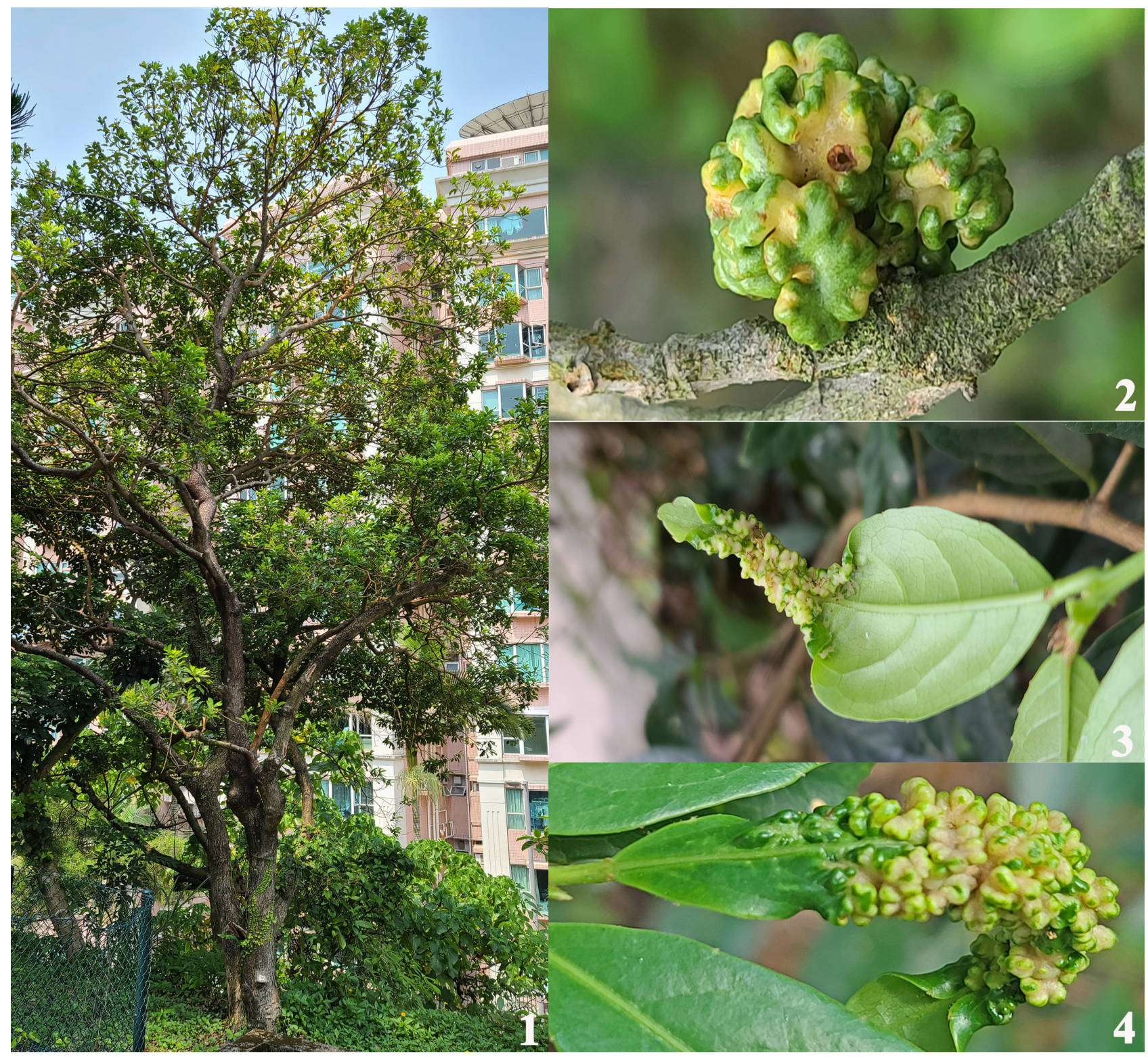

FIGURES 1-4. (1) Aporosa octandra; (2) Leaf gall (the early-season form); (3-4) Leaf gall (the late-season form).

\section{Material and methods}

The thrips specimens were macerated in 5\% NaOH solution for 4-8 hours. After dehydration through a series of ethanol concentrations, the specimens were then mounted onto slides in Canada balsam. Slide-mounted specimens were examined and photographed under the microscope with a digital camera attached and a digital microscope (Leica DFC450). The type series of this new species is deposited in the Insect Collection, South China Agricultural University (SCAU), Guangzhou, China.

\section{Psephenothrips aporosae sp. n.}

(Figs 5-21)

Female macroptera. Body dark brown (Figs 5, 9); distal halves of tibiae and tarsi yellowish brown; antennal segment II yellow shaded with brown basally, III-VI yellow and VII-VIII brown (Figs 5, 9 \& 10); fore wing shaded; tube yellowish brown at the base and distal third. Head approximately 1.3 times wider than long (Figs 7, 10); dorsal sur- 
face transversely reticulate, with a pair of minute setae at middle; ocellar region weakly sculptured with reticulation; cheeks straight, with a few tiny setae; postocular setae shorter than eyes, blunt or weakly expanded apically. Antennae 8-segmented (Fig. 6), III with one sense cone, IV with three sense cones, VIII shorter than VII, very weakly constricted at base. Mouth cone pointed, extending between fore coxae; maxillary stylets long, deeply reaching into eyes, close together medially (Fig. 7). Pronotum without median longitudinal apodeme, but transversely reticulate at anterior third and with some transverse anastomosing striae posteriorly (Fig. 8); five pairs of major setae developed, with apices softly rounded; epimeral and posteroangular setae much longer than the remaining setae, epimeral setae longest; pronotum notopleural suture variable, incomplete in holotype (Fig. 8), sometimes one side with complete suture, the other with incomplete suture. Fore femora slightly swollen, fore tarsal tooth absent (Fig. 11). Prosternal basantra absent, mesopresternum boat shape, without convex medially (Fig. 14). Mesonotum transversely reticulate (Fig. 9), lateral setae short. Metanotum sculptured with closely longitudinal reticulations, median setae small and slender (Fig. 12); metathoracic sternopleural sutures distinct (Fig. 16). Fore wing parallel-sided, with 8-9 duplicated cilia (Fig. 5); sub-basal setae long with apices softly rounded to weakly capitate, usually S3 longest (Fig. 15). Pelta hat shape, sculptured with polygonal reticulation, paired campaniform sensilla present (Fig. 13); tergites II-VII each with 2 pairs of sigmoid wing retaining setae; all abdominal major setae with knobbed apices except for wing retaining setae with acute apices; tergite IX setae blunt, setae S1 and S2 shorter than tube; tube slightly longer than head (Fig. 17).

Measurements. (holotype female in microns). Distended body length 2040. Head length (width) 170 (224); compound eyes dorsal length (width) 76 (60). Antennal segments I-VIII length (width) as follows: 40 (38), 46 (30), 60 (28), 58 (34), 58 (30), 54 (26), 48 (22), 34 (12). Postocular setae length 60. Pronotal median length (width) 150 (350); anteromarginal setae 30 , anteroangular setae 30 , midlateral setae 30 , epimeral setae 100 , posteroangular setae 85. Fore wing length 752; wing sub-basal S1 44, S2 56, S3 66. Abdominal tergite IX setae S1 134, S2 150; tube 190, anals about 115 .

Material examined. Holotype female, CHINA, Hainan Province, Danzhou City, the Danzhou Campus of Hainan University, 14.ix.2014, collected from the galls of Aporosa octandra [Phyllanthaceae], Shulan Yang. Paratypes: 4 females, same data as holotype. Non-paratypic specimens (deposited in the Insect Collection of the Inspection and Quarantine Branch of the Agriculture, Fisheries and Conservation Department, Hong Kong): 5 females, 5.v.2021, Hong Pak Country Trail, Hong Kong, collected from the galls of Aporosa octandra, Clive S. K. Lau.

Male. Unknown.

Etymology. The specific epithet is derived from the host plant genus name, Aporosa octandra, from which the specimens were collected.

Distribution. China (Hainan, Hong Kong).

Remarks. Psephenothrips aporosae sp. $\mathrm{n}$. cannot be placed in the keys to species of the genus provided by Wang and Lin (2020) and Dang et al. (2021). It is easily distinguished from its congeners by the head which is much shorter than its width as well as tube that is slightly longer than head. Although the head of $P$. leptoceras and P. moundi are relatively short, i.e., head almost as long as wide, the new species can be distinguished from both by the following combination of characteristics: (1) postocular setae blunt or knobbed distally, and shorter than eyes (versus slightly longer than eyes in leptoceras and as long as eyes in moundi); (2) fore wing with 8-9 duplicated cilia (versus 12 and 20-26 in leptoceras and moundi respectively); (3) mesopresternum boat shaped, without convex medially (versus boat shaped but with projection medially in leptoceras and moundi); (4) metanotum sculptured with closely longitudinal reticulation (versus metanotum almost smooth anteromedially in leptoceras and moundi).

Biology. Although Aporosa octandra is a dioecious angiosperm, the new species described here can induce leaf galls on both male and female plants. The galls caused by the thrips have an early-season form (Fig. 2) and a lateseason form (Figs 3, 4). Gall initiation for the early-season form appears to occur on young emerging leaves shortly after they bud out in late April and early May. As a result of feeding by the thrips, the lamina undergoes mesophyll hyperplasia and becomes distorted into a much-folded 'cerebrum-like' spherical leaf gall (Fig. 2). Because the budding leaf has a very short petiole, the gall may easily be mistaken as growing out directly from the twig. The gall is yellowish-green in colour with a diameter about $1.0-1.2 \mathrm{~cm}$. When the gall is manually unfolded (Fig. 18), the inside of gall is multilocular with many tightly folds, which could be considered as a protective strategy to keep gallinvaders or predators out. The first and second instar larvae are generally yellow except for antennae, head, pronotum and abdominal segment IX-X that are grey to dark (Figs 18, 19). However, these dark cuticles are progressively lost in the prepupa and pupal stages which progressively become yellow and transparent with internal orange and 


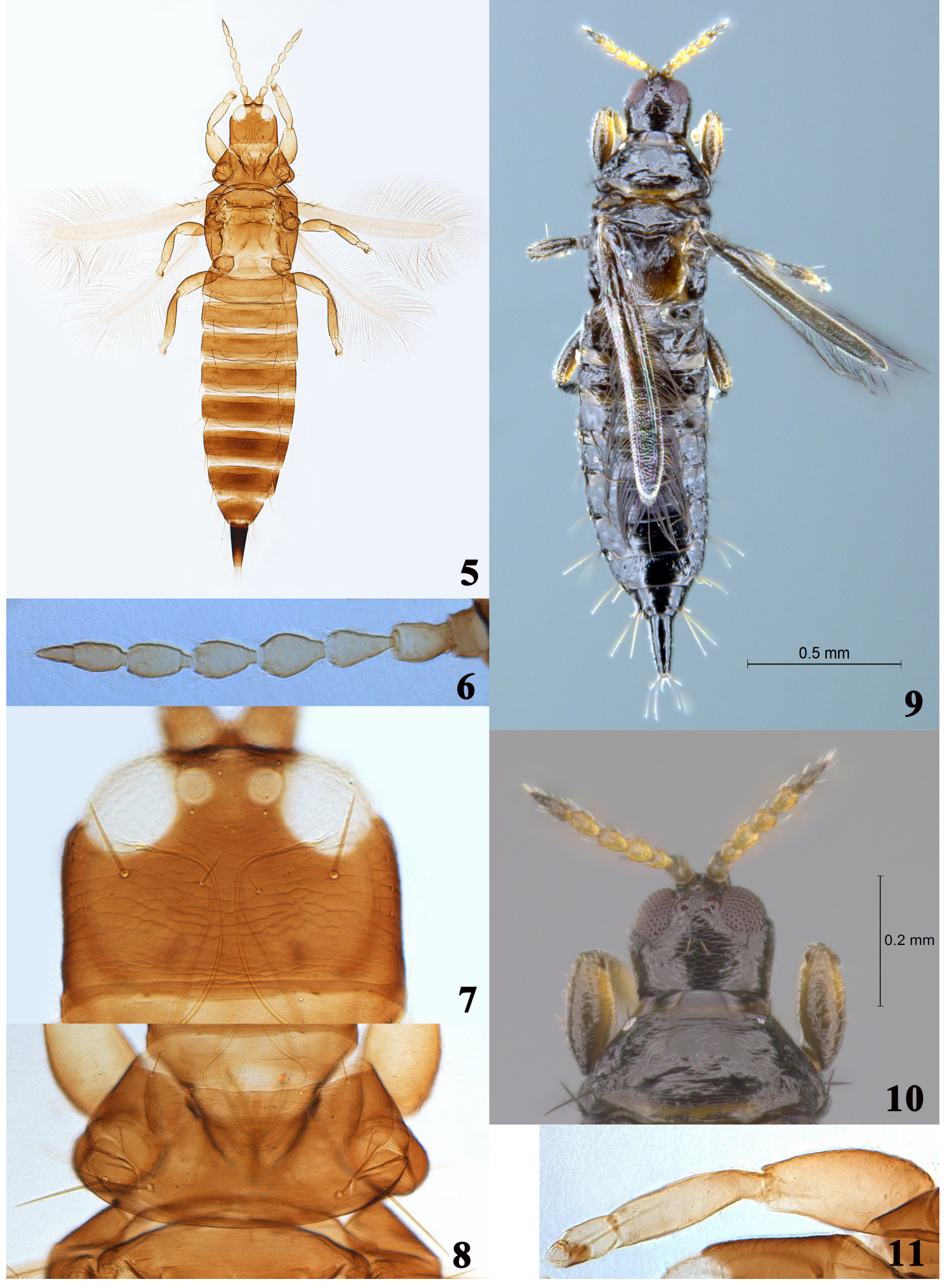

FIGURES 5-11. Psephenothrips aporosae sp. n., female: (5) P. aporosae sp. n. (female); (6) Antenna; (7) Head; (8) Pronotum; (9) P. aporosae sp. n. (image of digital microscope); (10) Head \& Pronotum (image of digital microscope); (11) Fore leg. 


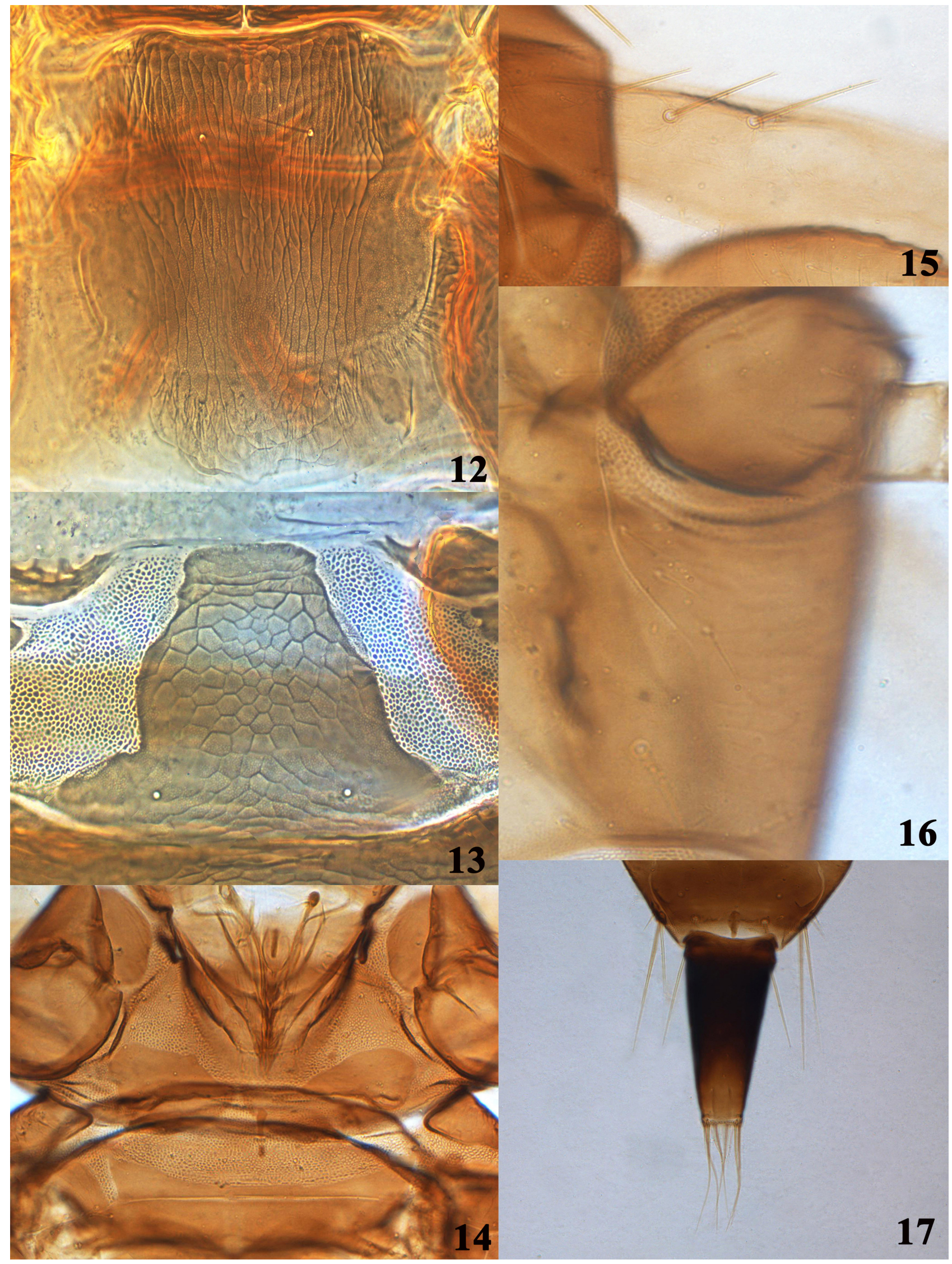

FIGURES 12-17. Psephenothrips aporosae sp. n., female: (12) Metanotum; (13) Pelta; (14) Pro- \& mesopresternum; (15) Subbasal setae of fore wing; (16) Metasternal sternopleural suture; (17) Tube. 
reddish pigments (Figs 20,21). The late-season gall is formed when the adult thrips leave the early-season gall to feed on fully grown leaves during Summer-Autumn period. This feeding can start anywhere on the leaves and is not restricted to beginning from the apex or petiole end. Epidermis hypertrophy occurs with simultaneous curling of the blade along the midrib, thus forming 'bubble-like' gall that extends half-way along a leaf (Figs 3, 4). In Hong Kong, Androthrips sp., a gall-invader that is commonly encountered in southern China, was observed wandering out of the gall. The density of leaf galls on Aporosa octandra does not seem to be high. According to the observations by the second author in three different localities of Hong Kong, the density remains at 1-3 galls per plant only.

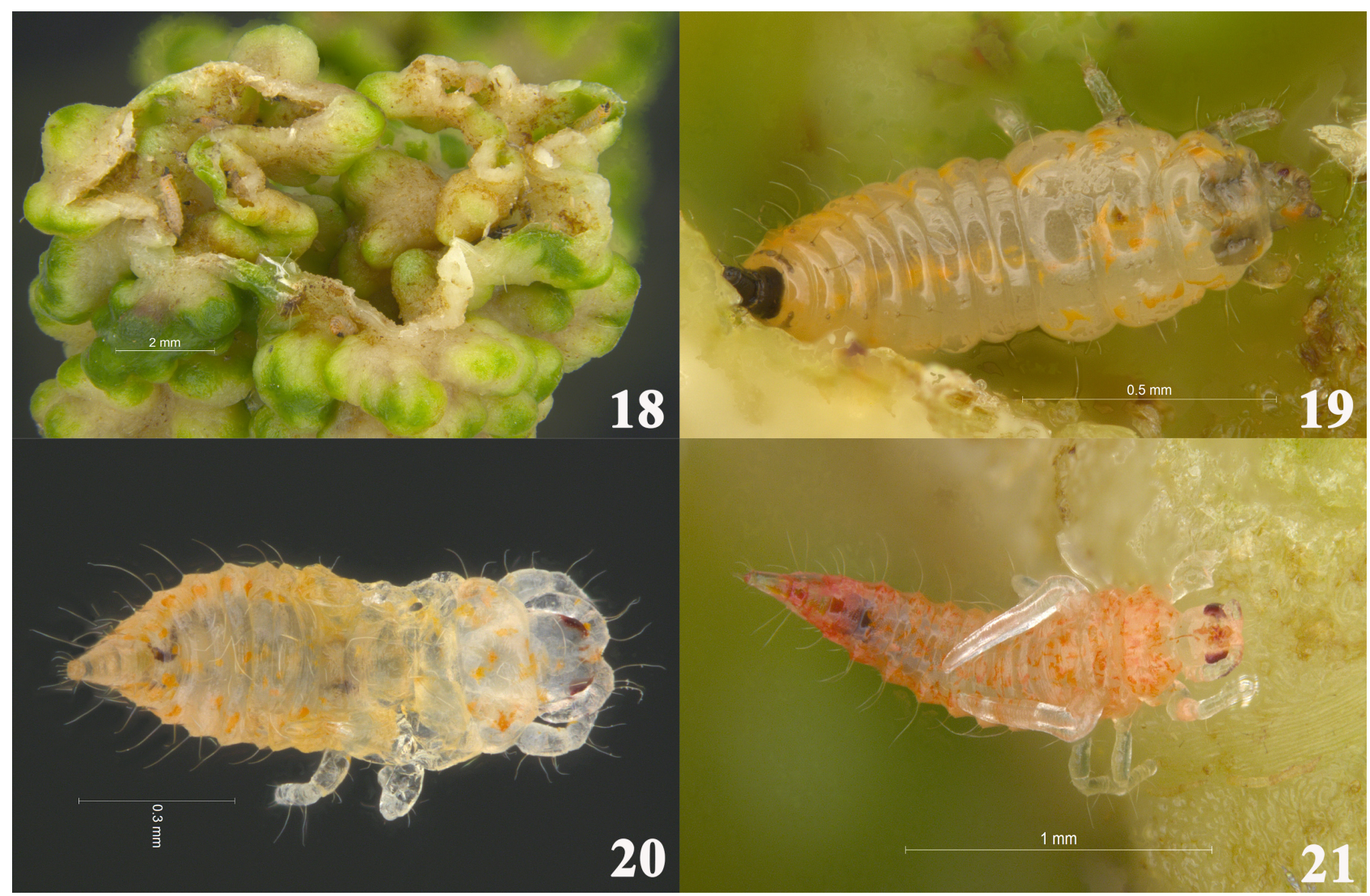

FIGURES 18-21. Life stages of Psephenothrips aporosae sp. n. (18) Inside of gall showing $2^{\text {nd }}$ instar larvae; (19) Second instar larva; (20) Prepupa; (21) Pupa.

\section{Acknowledgements}

This study was supported by the National Natural Science Foundation of China (No. 31372236). We are grateful to Shulan Yang for help with field work and the referees for their advice and constructive comments.

\section{References}

Dang, L.H., Mound, L.A. \& Qiao, G.X. (2014) Conspectus of the Phlaeothripinae genera from China and Southeast Asia. Zootaxa, 3807 (1), 1-82.

https://doi.org/10.11646/zootaxa.3807.1.1

Dang, L.H., Zhao, L.P., Li, Y.Q. \& Qiao, G.X. (2021) Studies on the genus Psephenothrips Reyes from China (Thysanoptera, Phlaeothripinae), with one new species. ZooKeys, 1029, 113-121. https://doi.org/10.3897/zookeys.1029.64531

Hoffman, P., Kathriarachchi, H. \& Wurdack, K.J. (2006) A phylogenetic classification of Phyllanthaceae (Malpighiales; Euphorbiaceae sensu lato). Kew Bulletin, 61 (1), 37-53.

Mound, L.A. (2020) Liothrips species (Thysanoptera, Phlaeothripinae) from leaf-galls on Piper species in Southeast Asia and Australia. Zootaxa, 4830 (2), 383-391.

https://doi.org/10.11646/zootaxa.4830.2.9 
Mound, L.A. \& Marullo, R. (1996) The Thrips of Central and South America: An Introduction. Memoirs on Entomology, International, 6, 1-488.

Okajima, S. (2006) The Suborder Tubulifera (Thysanoptera). The Insects of Japan. Vol. 2. The Entomological Society of Japan, Touka Shobo Co. Ltd., Fukuoka, 720 pp.

Reyes, C.P. (1994) The Thysanoptera of the Philippines. The Raffles Bulletin of Zoology, 42, 107-507.

ThripsWiki (2021) ThripsWiki_providing information on the World's thrips. Available from: http://thrips.info/wiki/Main_Page (accessed 2 October 2021)

Tyagi, K. \& Kumar, V. (2012) A new species of Psephenothrips (Thysanoptera: Phlaeothripidae) from India. Oriental Insects, 46, 281-287.

https://doi.org/10.1080/00305316.2012.752618

Wang, C.L. \& Lin, F.C. (2020) Genera and species of the Liothrips lineage (Thysanoptera, Phlaeothripinae) from Taiwan. Zootaxa, 4861 (3), 349-375.

https://doi.org/10.11646/zootaxa.4861.3.3 